\title{
Septic Arthritis of the Sacroiliac Joint: Case Report and Evolution 10 Years after Treatment
}

\section{Edir Soccol Junior ${ }^{1 *}$, Mauro Grinfelder ${ }^{2}$, Caroline Rafaela Solano ${ }^{3}$, Maria Eduarda Oro Dilly ${ }^{3}$, Willian Gustavo Tasca ${ }^{3}$, Rubia M Alves ${ }^{3}$, Lilian C Meneguzzo ${ }^{3}$, Neri Machado Junior ${ }^{1}$, Fabio Cavali ${ }^{1}$, Fernando Soccol $^{1}$, Haiana Cavalheiro ${ }^{1}$ and Ronan Bertinatto ${ }^{1}$}

${ }^{1}$ Department of Orthopedics and Traumatology of the Pato Branco Polyclinical Institute, Paraná, Brazil

${ }^{2}$ Orthopedics and Traumatology Resident, Department of Orthopedics and Traumatology of the Pato Branco Polyclinical Institute, Paraná, Brazil

${ }^{3}$ Medicine Student from the University Center of Pato Branco, Pato Branco, Paraná,

Brazil

*Corresponding Author: Edir Soccol Junior, Department of Orthopedics and Traumatology, Department of Hip and Pelvic Surgery of the Pato Branco Polyclinical Institute, Paraná, Brazil.
Received: March 20, 2021

Published: March 26, 2021

(C) All rights are reserved by Edir Soccol Junior., et al.

\begin{abstract}
Introduction: Case report of septic arthritis of the left sacroiliac joint, which after a difficult diagnosis it obtained effective treatment. The report compares image exams after 10 years of follow-up.

Objective: To present a case report about an 18-year-old youngster, male, with difficult diagnosis of the septic arthritis of the left sacroiliac joint condition, as well as the adopted therapy.

Methodology: The information present in this paper was taken from the anamnesis and the physical exams of the patient, medical and photographic records review of the diagnostic methods and the therapy adopted in the treatment; it has been performed a literature review.

Conclusion: This report seeks to call the colleagues attention to a rare disease of difficult diagnosis, which needs aggressive and well directed treatment in order to avoid severe sequelae of lower members or even death.
\end{abstract}

Keywords: Septic Arthritis; Left Sacroiliac Joint; Spondyloarthropathies; Reiter's Syndrome

\section{Introduction}

The alterations of the sacroiliac joints are associated to a great number of diseases. The inflammatory diseases are the most frequent and important, such as seronegative spondyloarthropathies, ankylosing spondylitis, Reiter's syndrome, arthropathy of inflammatory bowel diseases and psoriatic arthropathy [1].
The pyogenic sacroiliac joint infection (Septic Arthritis of the Sacroiliac Joint) is not common, it is relatively rare, and focuses more in male teenagers and young adults. It is necessary to point that reported cases of bilateral septic sacroiliitis are even rarer. In addition, its diagnosis can be difficult, thus having to be differentiated from septic arthritis of the hip, gluteal ulcers, psoas abscess, 
ilium osteomyelitis, sciatica, discitis, pyelonephritis, appendicitis and primary or metastatic neoplasms [1].

Septic Arthritis of the Sacroiliac Joint has cardinal clinical symptom of sacroiliac joint impairment which is the pain, possible to be diffuse in the low back and not only located in its anatomical site, it is little described as profound and frequently located in the upper inner quadrant of the buttock, irradiating to the posterior thigh region. Other times it can manifest itself as low back or hip pain [1,2].

Septic Arthritis of the Sacroiliac Joint had two forms of clinical condition presentation. The first is as an acute disease, feverish, with present infection signs, severe pain in the buttocks region and difficulty to walk (this presentation is more frequent). The second form is as a subacute disease, of slow evolution, without fever and less severe pain [2].

The diagnosis must be confirmed with sacroiliac puncture with needle or surgical biopsy to collect culture material. The most usually isolated microorganism is Staphylococcus aureus; other less depicted bacteria as Staphylococcus epidermidis, Streptococcus, Salmonella, Pseudomonas, Klebsiella and Neisseria gonorrhoeae [1,2].

Furthermore, magnetic resonance imaging (MRI) is considered, by several authors, as the chosen exam to confirm the diagnosis. The blood cultures and/or synovial fluid culture are fundamental for the identification of the pathogen [2].

The medical treatment consists of intravenous antibiotic therapy and abscess drainage for the cases which do not respond to antibiotic therapy, but many patients still have persistent radiological alterations in their evolution, and some maintain pain condition for some months [2].

\section{Case Report}

18-year-old patient sought outpatient care due to left hemipelvis pain which had been happening for a week. Pain located in the lumbosacral portion, difficult to characterize and without defined irradiation. The patient took anti-inflammatory drugs, but did not improve. He presented constitutional symptoms as fever, hypoxia and prostration. The lumbar spine and hip physical exams did not present any specific characteristic leading to the diagnosis. It was indicated hospitalization to additional investigation, diagnosis and treatment definition.
Of the additional exams, the simple x-ray and the total abdominal ultrasound did not show alterations, laboratorial exams with elevated inflammatory activity (very elevated ESR and CRP) and hemogram with bastonetosis and leukocytosis. The empirical antibiotic therapy was initiated, but without improvement of the symptoms. A deeper investigation with magnetic resonance imaging (MRI) of the pelvis showed altered signal intensity in the left sacroiliac joint suggesting edema and/or osteitis (Picture 1); the bone scintigraphy showed contrast uptake in the left sacroiliac joint (Picture 2), which led to suspicion of sacroiliitis.

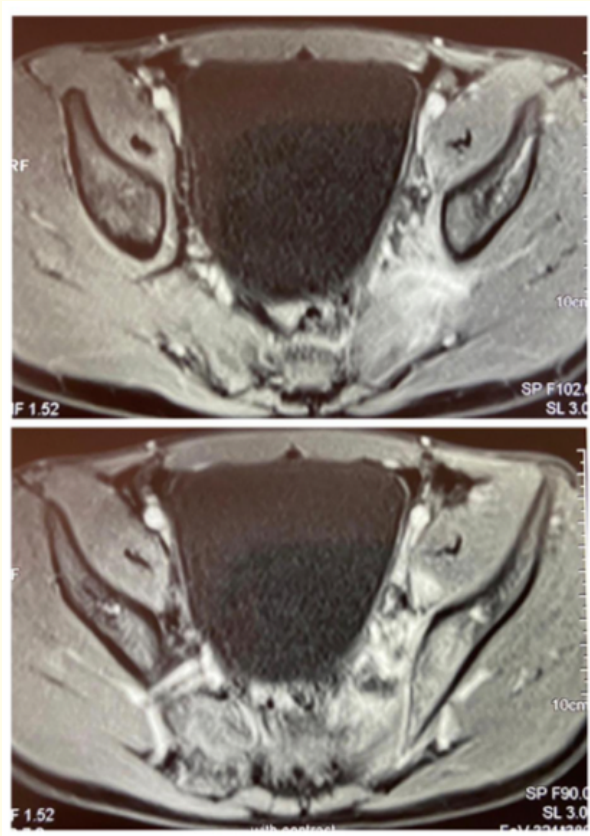

Picture 1: Pelvis MRI.

Therefore, it was performed a surgical treatment with abscess drainage, debridement and thorough washing of the left sacroiliac joint associated with broad-spectral antimicrobial therapy (Ciprofloxacin $500 \mathrm{mg} \mathrm{12/12h).}$

\section{Results}

After surgical treatment, the patient presented gradual condition improvement both local and systemic. He kept the use of the same antibiotic for 30 days, remained in physical therapy rehabilitation for 3 months, and now, after 10 years, does not present any walking sequelae or pain even during physical activities. However, 


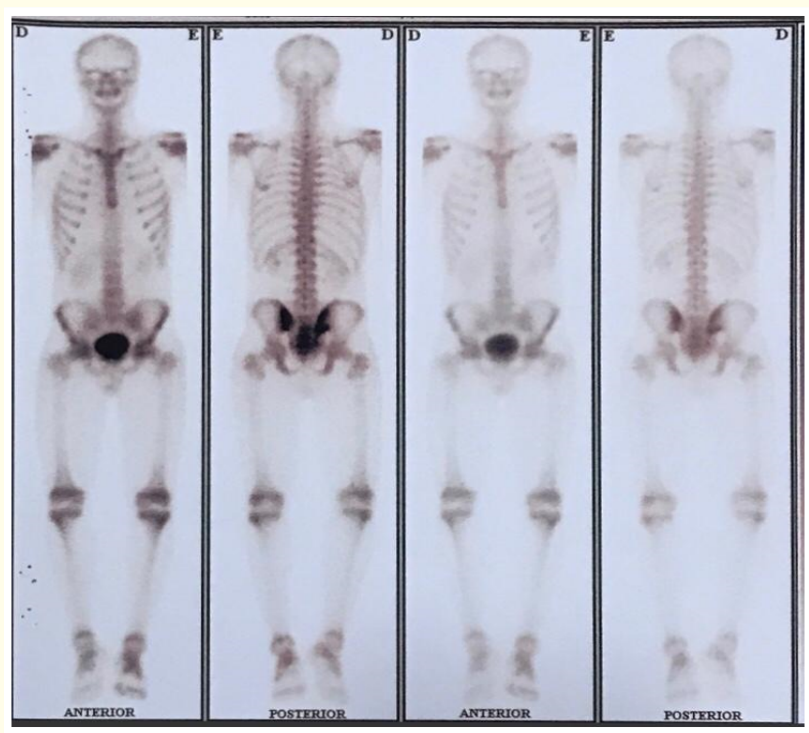

Picture 2: Bone scintigraphy.

his pelvis actual x-rays indicate ankylosis of the left sacroiliac joint and advanced degenerative process of the right sacroiliac joint as shown in picture 3 .

\section{Discussion}

As it is a potentially severe disease and of high morbidity if not diagnosed or treated aggressively and in advance, septic arthritis of the sacroiliac joint must always be remembered as an important differential diagnosis in unspecific cases of backaches associated with systemic symptoms.

It is necessary to remember that the infection normally has a hematogenous origin and a previous infection condition which can suggest the disease, especially in young men [3-7].

The clinical exam is unspecific, but it can be facilitated when the patient presents fever, posterior pain, pain to compression of the sacroiliac joint, present signs of Patrick and Gaenslen $[3,4]$. The laboratorial exams, on the other hand, will present leukocytosis and elevated inflammatory activity. In places where there are no advanced radiology centers with MRI or CT, the most accurate exam is Bone Scintigraphy [7].

In relation to the antibiotic therapy, a great part of the patients will answer to antibiotic therapy for 4 to 8 weeks, without long

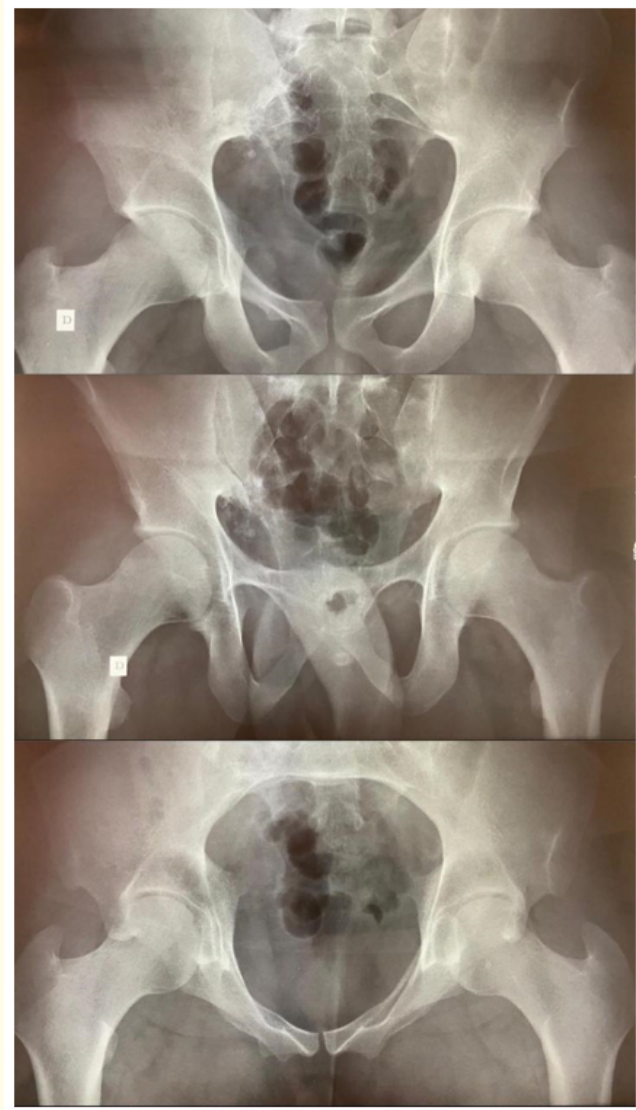

Picture 3: Pelvis actual x-rays.

term sequelae [3,8-17]. For patients who do not present improvement within 24 to 48 hours, it is indicated surgical drainage, with excellent results [5].

\section{Conclusion}

Finally, this report seeks to call the colleagues attention to a rare disease of difficult diagnosis, which needs aggressive and well directed treatment in order to avoid severe sequelae of lower members or even death.

\section{Bibliography}

1. Marques Filho José. "Sacroiliite séptica: relato de caso". Jornal de Pediatria 72.4 (1996): 258-262.

2. Oliveira Carolina., et al. "Sacroileíte Piogénica: Caso Clínico". Revista Portuguesa de Ortopedia e Traumatologia 25.1 (2017): 49-55. 
3. Hodgson BF. "Pyogenic Sacroiliac Joint Infection”. Clinical Orthopaedics 246 (1989): 146-149.

4. Aprin H and Turen C. "Pyogenic sacroileitis in children". Clinical Orthopaedics 287 (1993): 98-106.

5. Coy JT., et al. "Pyogenic arthritis of the sacroiliac joint - long term follow-up". Journal of Bone and Joint Surgery 58 (1976): 845-849.

6. Sultan J and Hughes JP. "Septic arthritis or transient synovitis of the hip in children". Journal of Bone and Joint Surgery 92 (2010): 1289-1293.

7. Abbott GT and Carty H. "Pyogenic sacroiliitis, the missed diagnosis?" The British Institute of Radiology 66 (1993): 120-122.

8. Shanahan MDG and Ackroyd CE. "Pyogenic infection of the sacroiliac joiont". Journal of Bone and Joint Surgery 67 (1985): 605608.

9. Scott J Luhmann A., et al. "Differentiation Between Septic Arthritis and Transient Synovitis of the Hip in Children with Clinical Prediction Algorithms". Journal of Bone and Joint Surgery 86 (2004): 955-962.

10. Don B Miskew., et al. "Aspiration of Infected Sacro-Iliac Joints". Journal of Bone and Joint Surgery 61 (1979): 1071-1072.

11. Patrick J Kelly MI., et al. "Bacterial Arthritis of the Hip in the Adult". Journal of Bone and Joint Surgery 45 (1965): 1005-1018.

12. Kocher Mininder S., et al. "A clinical practice guideline for treatment of septic arthritis in children: efficacy in improving process of care and effect on outcome of septic arthritis of the hip". Journal of Bone and Joint Surgery 85.6 (2003): 994-999.

13. Kelly Patrick J., et al. "Bacterial arthritis of the hip in the adult". Journal of Bone and Joint Surgery 47.5 (1965): 1005-1018.

14. Krishnan Venkatesh., et al. "Methicillin-resistant Staphylococcus aureus as a cause of lumbar facet joint septic arthritis: a report of two cases". Journal of Bone and Joint Surgery 92.2 (2010): 465-468.

15. Vyskocil James J., et al. "Pyogenic Infection of the Sacroiliac Joint Case Reports and Review of the Literature". Medicine 70.3 (1991): 188-197.
16. Mcgaughey Ingrid. "Pyogenic infection of the sacroiliac joint". Australian and New Zealand Journal of Surgery 66.5 (1996): 282-286.

17. March Allan W., et al. "Retroperitoneal abscess and septic arthritis of the hip in children: a problem in differential diagnosis". Journal of Bone and Joint Surgery 54.1 (1972): 67-74.

\section{Assets from publication with us}

- Prompt Acknowledgement after receiving the article

- Thorough Double blinded peer review

- Rapid Publication

- Issue of Publication Certificate

- High visibility of your Published work

Website: www.actascientific.com/

Submit Article: www.actascientific.com/submission.php

Email us: editor@actascientific.com

Contact us: +919182824667 